Acta vet. scand. $1976,17,261-263$.

Brief Communication

\title{
ISOLATION OF YERSINIA ENTEROCOLITICA FROM A DOG WITH CHRONIC ENTERITIS
}

A CASE REPORT

During recent years, Yersinia enterocolitica has been isolated from humans and various animal species in connection with intestinal disorders, such as acute ileitis and appendicitis. Cases of septicaemia, polyarthritis and erythema nodosum have also been described (Mollaret \& Destombes 1964, Nilehn 1969, Winblad 1969, Lassen 1972, Langford 1972). Y. enterocolitica has been isolated most frequently from chinchillas and hares, but sporadic isolations from deer, cow, horse, rabbit, goat and dog have been reported (Langford, Krogstad et al. 1972). In Norway, an outbreak of the disease in a goat herd is the only described case of yersiniosis among animal species (Krogstad et al.). A case of chronic enteritis in a dog from which $Y$. enterocolitica was isolated is presented in the following.

The dog, a 9 months old Whippet, had suffered from moderate diarrhoea and anorexia from 6-7 weeks of age, interrupted by shont periods with normal consistency of the faeces. The dog was killed because repeated treatment with different antibiotics and chemotherapeutica had no obvious effect.

The necropsy revealed that the dog was emaciated and dehydrated. There were almost hairless spots up to $5 \mathrm{~mm}$ in diameter and covered with dry scaly crusts in the skin on the ventral parts of the thorax and abdomen. The mucosa of the small intestine was hyperaemic and seemed thickened. The intestinal contents were mucous and scanty throughout the intestine. The mesenterial lymph glands were slightly enlarged.

Histological examination of the different sections of the intestines showed a moderate increase in connective tissue in the lamina propria together with a pronounced plasma cell proliferation. In the ileum, the lymphoid follicles appeared atrophic with strands of connective tissue through the sparse lymphoid cell 
collections which also contained plasma cells and some macrophages with PAS (Periodic acid-Schiff method) positive granules in the cytoplasm.

In the mesenterial lymph glands, there was a marked plasma cell proliferation in the medullary cords and massive collections of macrophages, with PAS-positive granula in the cytoplasm, in the medullary sinus. In the prescapular and popliteal lymph glands the changes were almost identical with those in the mesenterial lymph glands, except for the occurrence of a few polymorphonuclear cells in the sinus. Epidermis in the altered parts revealed hyperkeratosis with dense infiltrations of polymorphonuclear cells in the crusts and varying neutrophilic infiltrations of the corium. In addition, there were scattered collections of lymphocytes, plasma cells and macrophages sometimes at perivascular sites in the corium and subcutis.

On bacteriological examination of the contents of the intestinal tract, bacteria were found which satisfied the criteria for Y. enterocolitica (Buchanan \& Gibbons 1974). In addition, a Citrobacter species was isolated. Serological examinations of the Yersinia strain were performed as described by Winblad (1968) and it was found to belong to Y.enterocolitica serotype 3. Biochemically, the strain belongs to biotype 4 , but differed from the standard criteria by causing a zone of haemolysis after 4 days of incubation at $30^{\circ} \mathrm{C}$ on blood agar.

Although Y. enterocolitica was isolated in connection with the present case of chronic enteritis, this does not necessarily mean that the bacterium was the causative agent of the disease, nor does the pathological picture give any definite answer. No microabscesses in the mesenterial lymph glands were found as described in man by Mollaret \& Destombes. From an epidemiological point of view, it is interesting to note that almost every human strain of $\mathbf{Y}$. enterocolitica isolated in Norway also belongs to serotype 3 (Lassen). However, none of the persons who had been in daily contact with the dog had suffered from diarrhoea or abdominal pain.

\section{Farstad, T. Landsverk and J. Lassen}

The Department of Microbiology and Immunology and

the Department of Pathology, Veterinary College of Norway, Oslo and the National Institute of Public Health, Oslo, Norway. 


\section{REFERENCES}

Buchanan, R. E. \& N. E. Gibbons: Bergey's Manual of Determinative Bacteriology, 8th Ed. The Williams \& Wilkins Company, Baltimore 1974.

Krogstad, O., J. Teige jr. \& J. Lassen: Yersinia enterocolitica type 2 associated with disease in goat. Acta vet. scand. 1972, 13, 594596.

Langford, E. V.: Yersinia enterocolitica isolated from animals in the Fraser Valley of British Columbia. Canad. vet. J. 1972, 13, 109113.

Lassen, J.: Yersinia enterocolitica - sykdom og diagnostikk. (Yersinia enterocolitica - disease and diagnosis). T. norske Lægeforen. 1972, 92, 567-569.

Mollaret, H. H. \& P. Destombes: Les germes X en pathologie humaine. (Bacterium $X$ in human pathology). Presse méd. 1964, 72, 2913 $\mathbf{2 9 1 5 .}$

Nilehn, Birgitta: Studies on Yersinia enterocolitica with special reference to bacterial diagnosis and occurrence in human acute enteric disease. Acta path. microbiol. scand. 1969. Suppl. 206, $48 \mathrm{pp}$.

Winblad, S.: Studies on O-antigen factors of Yersinia enterocolitica. Int. Symp. Pseudotuberculosis, Paris 1967. Symp. Series. Immunobiol. Standard, Karger, Basel/New York, 1968, 9, 337-342.

Winblad, S.: Erythema nodosum associated with infection with Yersinia enterocolitica. Scand. J. infect. Dis. 1969, 1, 11-16.

(Received April 12, 1976).

Reprints may be requested from: L. Farstad, the Department of Food Hygiene, Veterinary College of Norway, Postbox 8146, Oslo Dep., Oslo 1, Norway. 